\title{
Mesoporous Silica: An Efficient Nano-Reactor for Liquid-Liquid Biphase Reactions
}

Renyuan Zhang, Wei Ding, Bo Tu, Dongyuan Zhao*

\section{Supporting information}

\section{Experiment Section}

Mesoporous silicates: SBA-15 materials were prepared by using triblock copolymer Pluronic $\mathrm{P} 123\left(\mathrm{EO}_{20}-\mathrm{PO}_{70}-\mathrm{EO}_{20}\right)$ as a structure-directing agent under acidic condition according to the previous literatures. ${ }^{2}$ In the same batch, hydrothermal treatments with different temperatures and times resulted in different pore size of SBA-15s. MCM-41 was prepared by using cationic surfactant cetyltrimethylammonium bromide (CTAB) as a structure-directing agent under basic condition. ${ }^{18}$ The calcinations were carried out at $550^{\circ} \mathrm{C}$ in air for $5 \mathrm{~h}$ to remove the template for all of the mesoporous silicates.

Functionalization: 3-Aminopropyl functionalized SBA-15 (denoted as SBA-15- $\mathrm{NH}_{2}$ ) was obtained via a refluxing process of $0.221 \mathrm{~g} \quad\left(\begin{array}{lll}\mathrm{mmol}\end{array}\right)$ of 3-aminopropyltriethoxysilane (APTES) and $1.0 \mathrm{~g}$ of SBA-15-c with pore size of 8.2 $\mathrm{nm}$ in dried toluene at $120^{\circ} \mathrm{C}$ for $12 \mathrm{~h}$. Methyl-modified SBA-15 (denoted as SBA-15- $\mathrm{CH}_{3}$ ) was prepared via a refluxing process of $0.1 \mathrm{~g}$ of methyltriethoxysilane (MTES) and $1.0 \mathrm{~g}$ of SBA-15-c with pore size of $8.2 \mathrm{~nm}$ in toluene at $120^{\circ} \mathrm{C}$ for $12 \mathrm{~h}$. Fourier transform infrared (FTIR) spectra of modified SBA-15 were shown in Figure S4.

SBA-15- $\mathrm{WO}_{4}{ }^{2-}$ : For a typical preparation of the grafted catalyst SBA-15- $\mathrm{WO}_{4}{ }^{2-}, 0.5 \mathrm{~g}$ of SBA-15- $\mathrm{NH}_{2}$ was mixed with $0.30 \mathrm{~g}(2.0 \mathrm{mmol})$ of $\mathrm{CF}_{3} \mathrm{SO}_{3} \mathrm{H}$ and stirred in $\mathrm{CH}_{2} \mathrm{Cl}_{2}$ for $8 \mathrm{~h}$, and then filtered off, washed with $\mathrm{EtOH}$ and dried in vacuum at $40^{\circ} \mathrm{C}$ overnight. The obtained powder was mixed with $0.055 \mathrm{~g}(0.167 \mathrm{mmol})$ of sodium tungstate and stirred in water overnight. A white powder was filtered off, washed with large amount of water and dried in vacuum at $40^{\circ} \mathrm{C}$ overnight to furnish the grafted catalyst SBA-15- $\mathrm{WO}_{4}{ }^{2-}$, which was similar to the literature method. ${ }^{16}$ The grafted 
amount of sodium tungstate was $0.29 \mathrm{mmol} / \mathrm{g}$, measured by ICP analysis for the leaching solution.

Characterizations: The XRD patterns were recorded with a Bruker D4 powder X-ray diffractometer using $\mathrm{Cu} \mathrm{K} \alpha$ radiation $(40 \mathrm{kV}, 40 \mathrm{~mA})$. Nitrogen sorption isotherms were measured with a Micromeritics Tristar 3000 analyzer at $77 \mathrm{~K}$. Before the measurements, the sample was degassed in vacuum at $180^{\circ} \mathrm{C}$ for at least $6 \mathrm{~h}$. The Brunauer-Emmett-Teller (BET) method was utilized to calculate the surface areas. The pore size distributions were Barrett-Joyner-Halanda (BJH) method. The TEM images were recorded on a JEOL 2011 microscope operated at $200 \mathrm{kV}$. The FTIR spectra were collected on a Nicolet Fourier spectrophotometer. The ICP analyses were measured with a Thermo Elemental IRIS Intrepid. The UV spectra were recorded on a JASCO UV-550 (Japan).

Oxidation Reactions: All the oxidation reactions were carried out at $90^{\circ} \mathrm{C}$ under an organic solvent-free condition. For a typical procedure of benzyl alcohol oxidation, $2.16 \mathrm{~g}(0.02 \mathrm{~mol})$ of benzyl alcohol, $7.90 \mathrm{~g}(0.07 \mathrm{~mol})$ of $30 \mathrm{wt} \% \mathrm{H}_{2} \mathrm{O}_{2}$ and $0.23 \mathrm{~g}$ of SBA-15- $\mathrm{WO}_{4}{ }^{2-}$ were mixed together with stirring at $90^{\circ} \mathrm{C}$ for $12 \mathrm{~h}$. The catalyst was recovered from the reaction mixture by filtration. When the leaching mixture was cooled down to room temperature, $15 \mathrm{ml}(45 \mathrm{mmol})$ of $3.0 \mathrm{M} \mathrm{NaOH}$ was added. The benzyl alcohol and benzaldehyde were extracted with ether for 3 times. After that, 20 $\mathrm{ml}$ of $3.0 \mathrm{M} \mathrm{HCl}$ was added into the aqueous raffinate, and then the mixture was extracted with ether for 3 times. $2.05 \mathrm{~g}$ of benzyl acid was obtained from the ether phase with an isolated yield of $84 \% .{ }^{1} \mathrm{H}$ NMR (Bruker $\left.500 \mathrm{MHz}, \mathrm{CDCl}_{3}\right) \delta 7.48$ (dd, $2 \mathrm{H}, J=7.3,7.3 \mathrm{~Hz}), 7.62(\mathrm{dt}, 1 \mathrm{H}, J=1.5,7.3 \mathrm{~Hz}), 8.13(\mathrm{dd}, 2 \mathrm{H}, J=1.5,7.3 \mathrm{~Hz})$, 12.40 (brs, $1 \mathrm{H})$. Boiling point analysis: $249-251^{\circ} \mathrm{C}$.

In order to obtain high selectivity of benzaldehyde, a low $\mathrm{H}_{2} \mathrm{O}_{2} / \mathrm{BzOH}$ molar ratio was adopted under an inert atmosphere $\left(\mathrm{N}_{2}\right)$ or an airtight condition. In this case, $2.16 \mathrm{~g}(0.02 \mathrm{~mol})$ of benzyl alcohol, $2.70 \mathrm{~g}(0.024 \mathrm{~mol})$ of $30 \mathrm{wt} \% \mathrm{H}_{2} \mathrm{O}_{2}$ and $0.23 \mathrm{~g}$ of SBA-15- $\mathrm{WO}_{3}$ were mixed together with stirring at $90^{\circ} \mathrm{C}$ for $12 \mathrm{~h}$. The catalyst was recovered from the reaction mixture by filtration. When the leaching mixture was cooled down to room temperature, $15 \mathrm{ml}(45 \mathrm{mmol})$ of $3.0 \mathrm{M} \mathrm{NaOH}$ was added and 
then the mixture was extracted with ether for 3 times. The benzaldehyde was measured from the ether phase by GC (Themal) analysis using toluene as the standard and a yield of $68 \%$ was obtained. Beside that, the pure benzaldehyde was obtained by flash column chromatography (silica gel, petroleum ether/ethyl acetate, 4:1) with an isolated yield of $66 \%{ }^{1} \mathrm{H} \mathrm{NMR}\left(500 \mathrm{MHz}, \mathrm{CDCl}_{3}\right) \delta 7.54(\mathrm{dd}, 2 \mathrm{H}, J=7.5,7.8 \mathrm{~Hz})$, $7.64(\mathrm{dt}, 1 \mathrm{H}, J=1.5,7.5 \mathrm{~Hz}), 7.89$ (dd, 2H, $J=1.5,7.8 \mathrm{~Hz}), 10.03(\mathrm{~s}, 1 \mathrm{H})$. 


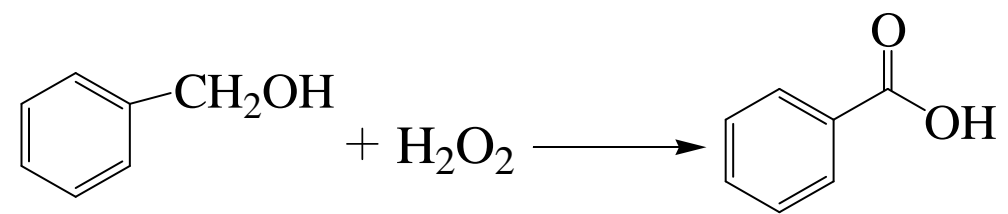

Scheme S1. The oxidation reaction of benzyl alcohol to benzoic acid using aqueous hydrogen peroxide as an oxidant.

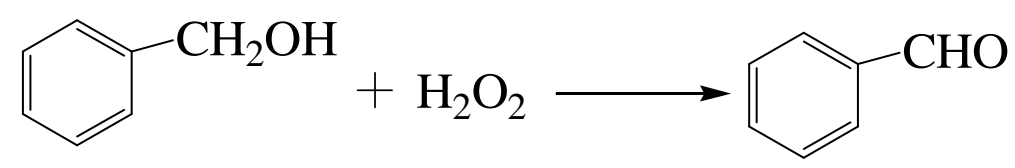

Scheme S2. The oxidation reaction of benzyl alcohol to aldehyde using aqueous hydrogen peroxide as an oxidant.<smiles>O=C(O)c1ccc([N+](=O)[O-])cc1</smiles>

Scheme S3. The oxidation reaction of p-nitrobenzyl alcohol to acid using aqueous hydrogen peroxide as an oxidant.<smiles>CC(=O)c1ccccc1</smiles>

Scheme S4. The oxidation reaction of phenethyl alcohol to acetophenone using aqueous hydrogen peroxide as an oxidant. 


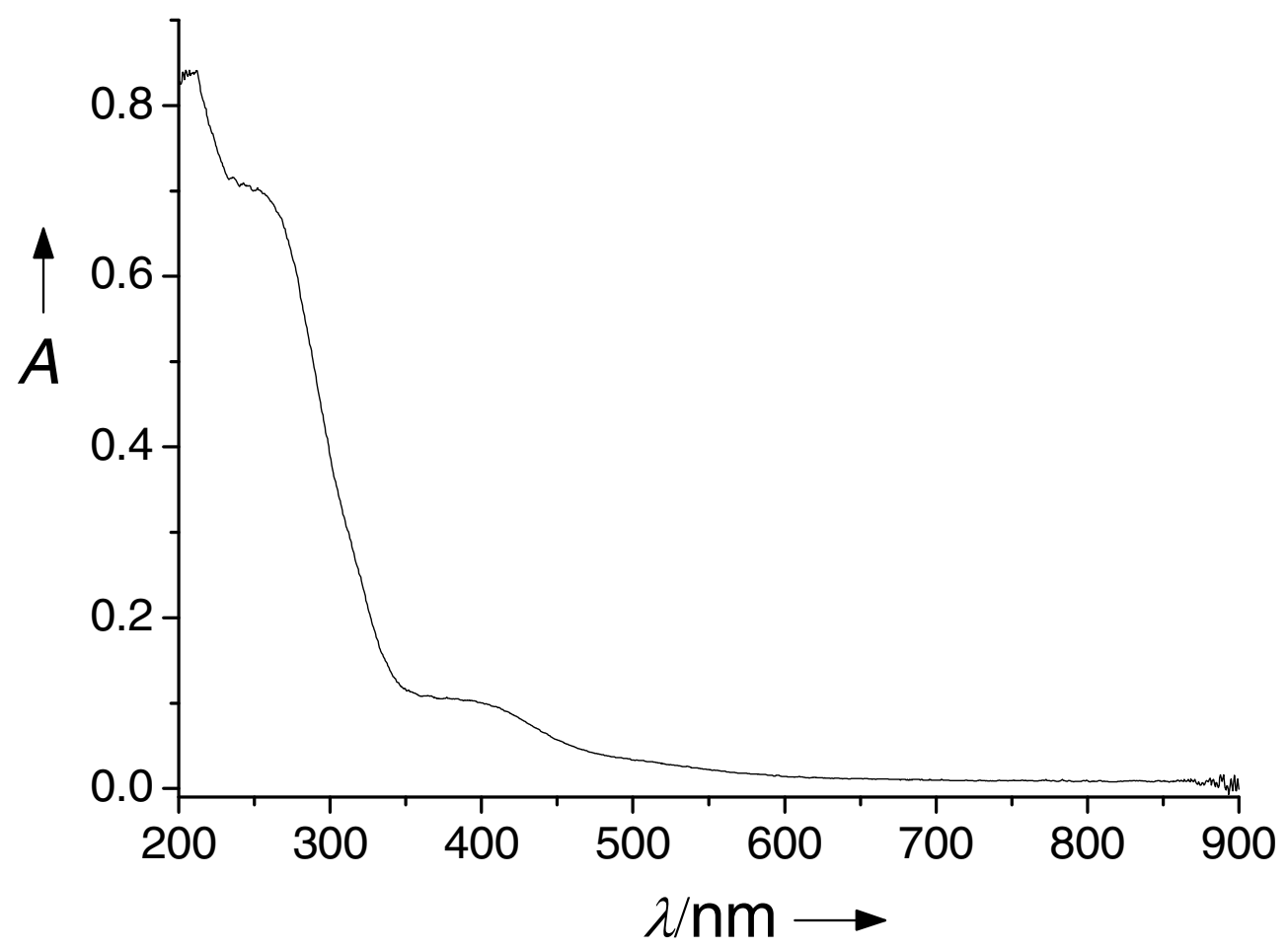

Figure S1. UV diffuse reflection spectrum (UV-DRS) of SBA-15- $\mathrm{WO}_{4}{ }^{2-}$ catalyst. The spectrum was recorded on a UV-550 (JASCO Japan). It shows that the tungstates are immobilized into the channels of SBA-15-c. 


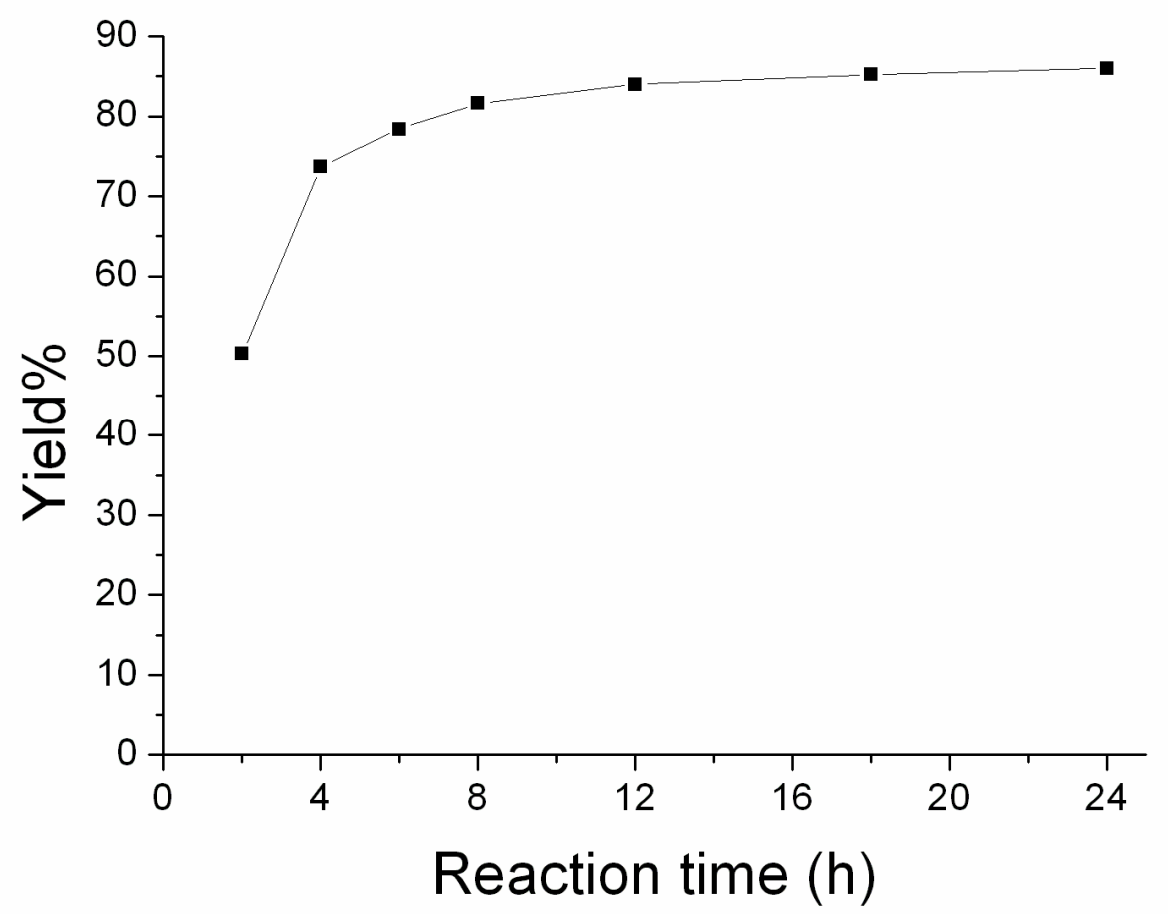

Figure S2. The oxidation reaction yield of benzyl alcohol functioned with the reaction time by using $\mathrm{SBA}-15-\mathrm{WO}_{4}{ }^{2-}$ as a catalyst. 


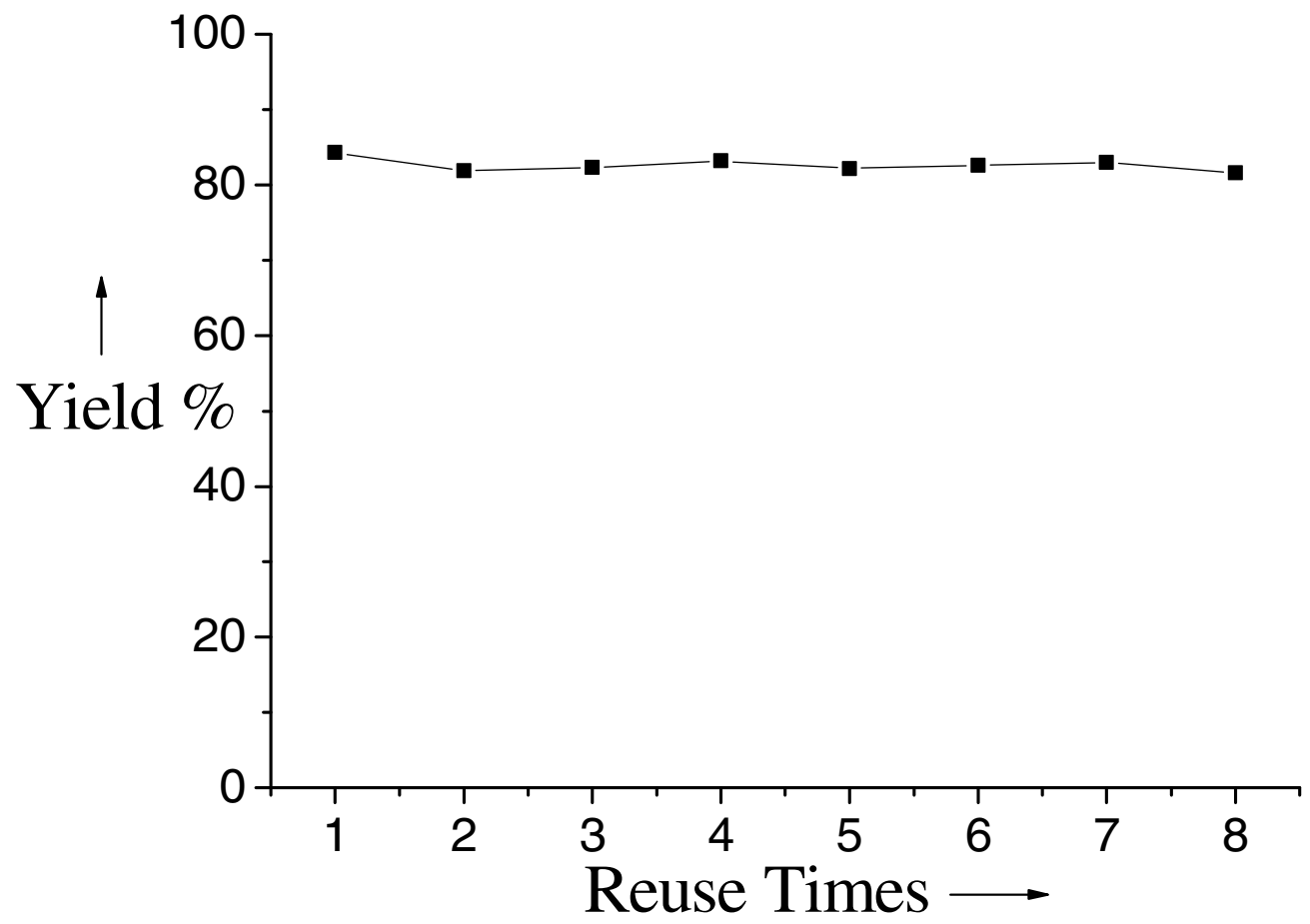

Figure S3. The oxidation reaction yield of benzyl alcohol functioned with the reused times by using SBA-15- $\mathrm{WO}_{4}{ }^{2-}$ as a catalyst. 


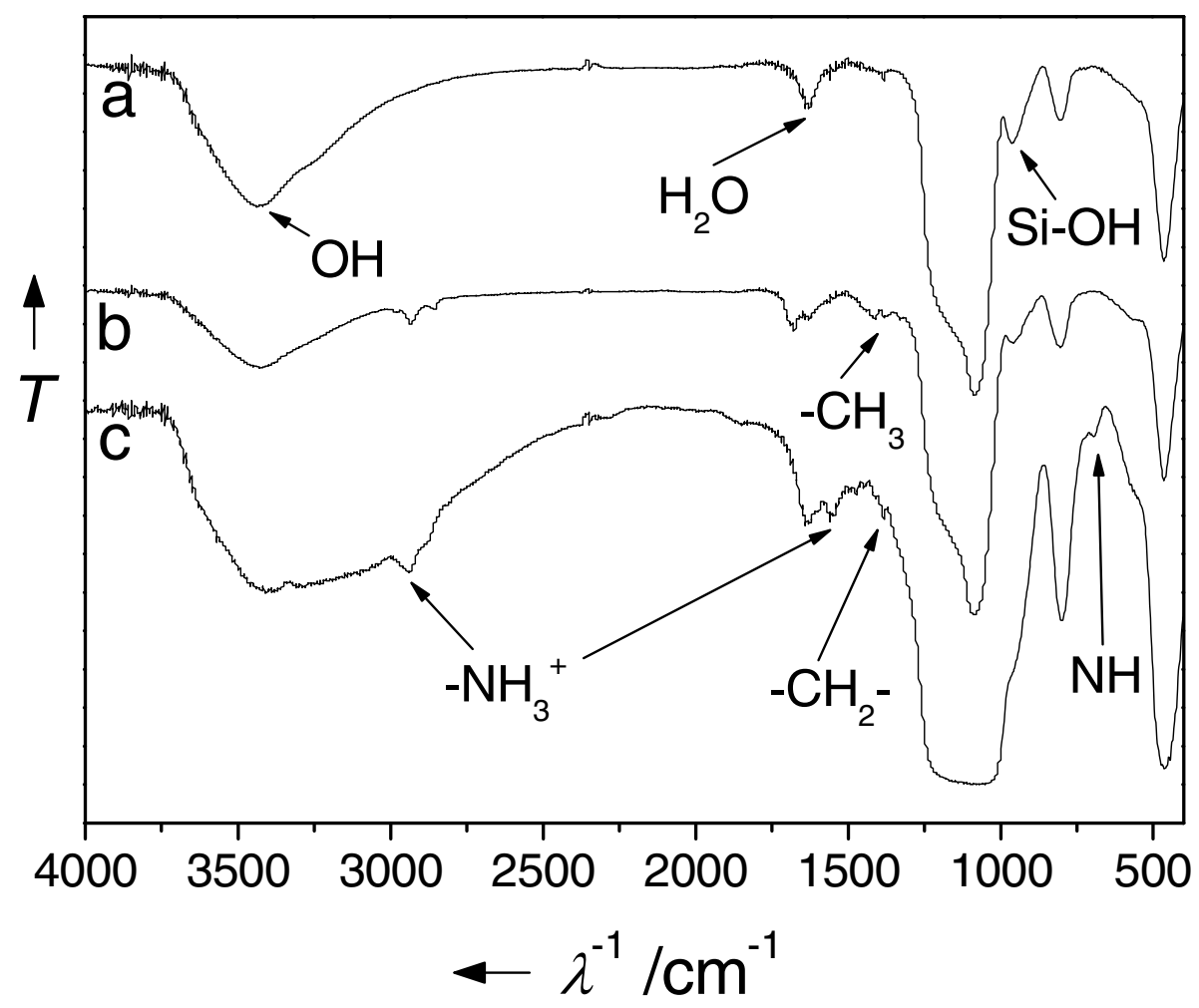

Figure S4. Fourier transform infrared (FTIR) spectra of a) SBA-15-c, b) SBA-15-CH and c) SBA-15-NH . It confirms that the functional groups $\left(-\mathrm{NH}_{2}\right.$ and $\left.-\mathrm{CH}_{3}\right)$ have been grafted on the surface of mesoporous silica SBA-15-c. 
Table S1. The oxidation of benzyl alcohol by using tungstates supported on mesoporous silica with different pore size as a catalyst. ${ }^{\text {a }}$

\begin{tabular}{ccccc}
\hline Entry & $\begin{array}{c}\text { Mesoporous } \\
\text { silica }\end{array}$ & $\begin{array}{c}\text { Pore size } \\
(\mathrm{nm})\end{array}$ & $\begin{array}{c}\text { Surface area } \\
\left(\mathrm{m}^{2} / \mathrm{g}\right)\end{array}$ & Yield\% \\
\hline 1 & MCM-41 & 2.4 & 940 & 71 \\
2 & SBA-15-a & 5.8 & 638 & 76 \\
3 & SBA-15-b & 6.8 & 766 & 89 \\
4 & SBA-15-c & 8.2 & 721 & 84 \\
5 & SBA-15-d & 10.2 & 501 & 81 \\
6 & SBA-15-CH $_{3}{ }^{\text {b }}$ & 8.1 & 676 & 57 \\
\hline
\end{tabular}

a. Reaction conditions: $\mathrm{S} / \mathrm{C}=300$, stirring at $90^{\circ} \mathrm{C}$ for $12 \mathrm{~h}$. The grafted amount of tungstate for each sample was $0.29 \mathrm{mmol} / \mathrm{g}$. b. This material was obtained by MTES modified SBA-15-c. 